\title{
A new technique for measuring kinetic and mass transfer parameters in flocs of Saccharomyces cerevisiae
}

\author{
A.A. Vicente, M. Dluhý and J.A. Teixeira* \\ Departamento de Engenharia Biológica, Universidade do Minho, Campus de Gualtar, 4709 Braga codex, Portugal
}

Yeast flocs are very fragile and cause problems when manipulations are needed. A new equipment for measuring kinetic and mass transfer parameters was developed and tested: the specific $\mathrm{O}_{2}$ uptake rate, $q_{\mathrm{O} 2}$, was calculated for a highly flocculent strain of Saccharomyces cerevisiae and its validation was confirmed by comparing the obtained kinetic parameters with data reported in titerature.

\section{Introduction}

The use of high cell density systems is now common as it presents many advantages (Galazzo and Bailey, 1990; Gianerto et al., 1988; Katzbauer et al., 1995; Laplace tt al., 1993; Willaert and Baron, 1994), including the one of an increased productivity. One of the techniques used to achieve such high cell concentration in a bioreactor is the use of flocculating properties of some microorganisms, which is worthwhile because of lower operating costs and design simplicity (Sousa and Teixeira, 1991; Sousa et al., 1994).

Yeast flocs are mechanically very sensitive aggregates which are very difficult to handle without damaging their integrity. Nevertheless, kinetic parameters and diffusivity values of nutrients and/or fermentation products are very important to characterize those aggregates and to study and optimize the processes in which they are involved (Hamdi, 1995; Pereboom, et al., 1990). Although thorough research work has been made in this area with other high cell density systems (of which cell immobilization in alginate beads is the most used) (Handrikiova et al., 1996; Kurosawa et al., 1989; Øyaas et al., 1995; Riley et al., 1996; Tanaka et al., 1984), very little practical work has been done with flocs (Sousa and Teixeira, 1991; Teixeira and Mota, 1990; Ananta et al., 1995), probably due to their fragility.

The aim of the present work is to provide a new system coupled with a new rechnique to determine kineric and mass cransfer parameters in yeast flocs. The system has been designed in order to minimize the stresses responsible for the destruction of the flocs' structure, while keeping good mixing characteristics. Being so, the method may be employed with other immobilization techniques, particularly those making use of small solid particles. As a test, the oxygen uptake rate for a flocculating yeast under respiro-fermentative metabolism was determined and compared with values found in the literature.

\section{Materials and methods \\ Yeast flocs}

The flocs used in the present work were obtained from a highly focculent strain of Saccharomyces ceretisiat NRRL $\mathrm{Y} 265$, grown continuously in an airlift bioreactor at $30{ }^{\circ} \mathrm{C}$ and $\mathrm{pH} 4$. Details on the reactor, the composition of the medium and the conditions of operation have been described elsewhere (Sousa tt al., 1994; Vicente and Teixeira, 1995; Vicente et al., 1996).

After being sampled, the aggregates were washed with tap water and resuspended in medium.

\section{Measuring equipment}

The device used in the experiments is represented in Fig. 1.

It consists mainly of an isolated measuring chamber (1) with a polarographic dissolved $\mathrm{O}_{2}$ probe (3) and a thermostated reservoir (2). Both compartments were made of Perspex. Mixing was provided by magnetic rods $(5 a, b)$ and gas supply to the reservoir was achieved through a gas sparger (7) with 5 holes (diameter $1 \mathrm{~mm}$ ).

Both vessels were kept hermetically closed by means of a rubber sealing plug (6) and an O-ring (14), respectively. The measuring chamber, when completely 


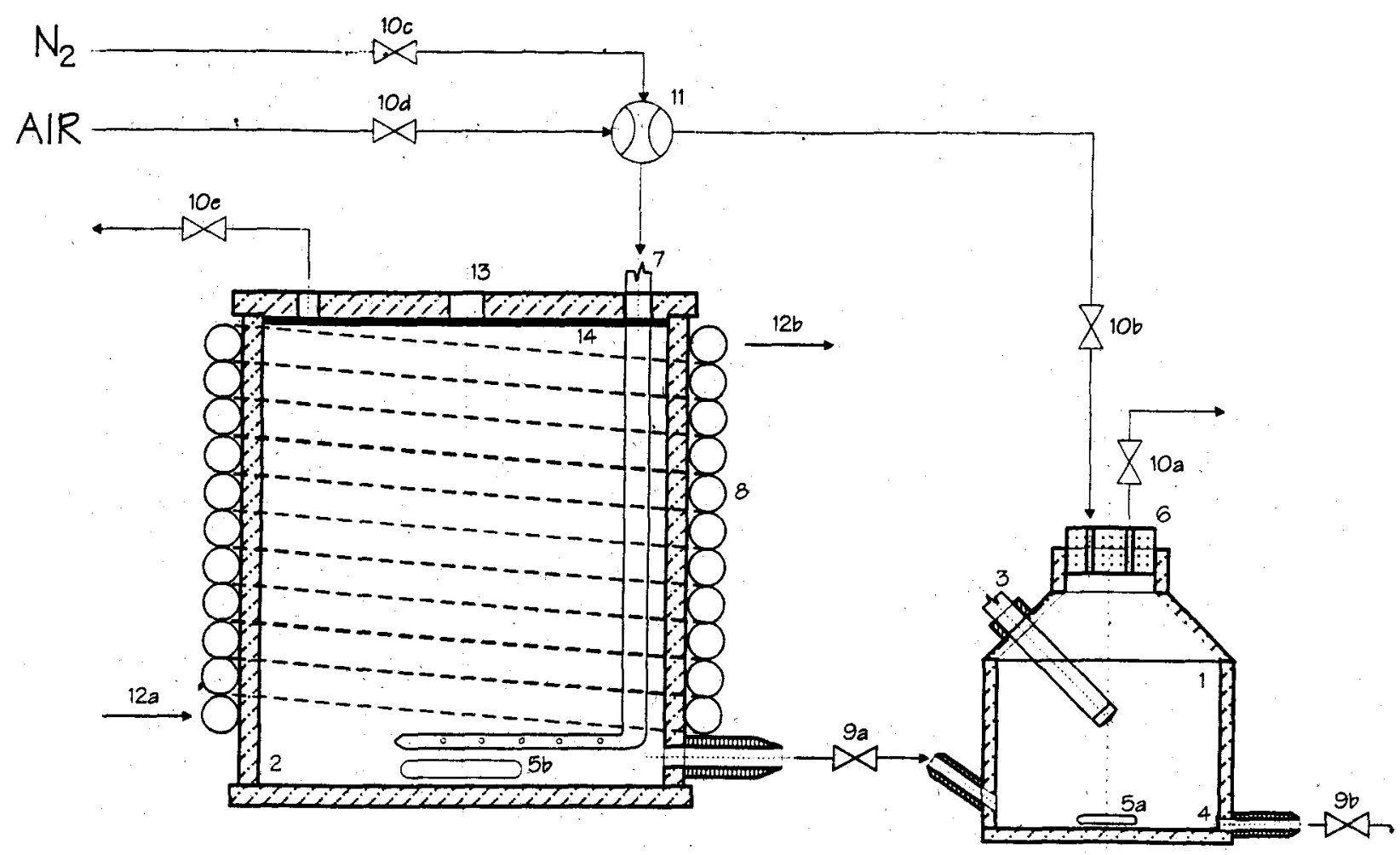

Figure 1 Experimental setup: (1) isolated measuring chamber (isolation now shown); (2) reservoir; (3) $\mathrm{DO}_{2}$ probe; (4) stainless steel mesh; (5a,b) magnetic rod; (6) rubber sealing plug; (7) gas sparger; (8) thermostated jacket; (9a,b) and (10a-e) one-way valves; (11) two-way valve; (12a,b) circulating thermostated liquid; (13) thermometer; (14) rubber sealing O-ring.

prepared for measurement, has a volume of $269 \mathrm{~mL}$ and the reservoir has an approximate volume of $2000 \mathrm{~mL}$.

\section{Experimental procedure}

The reservoir was filled with medium (including $50 \mathrm{~g}$ glucose/L as the carbon source) and pure $\mathrm{N}_{2}$ was introduced - into it in order to displace the dissolved $\mathrm{O}_{2}$. Meanwhile, the suspension of flocs was poured into the measuring chamber $(-5 \% \mathrm{v} / \mathrm{v})$ and the liquid phase was drained out (valve 9b) under $N_{\text {. }}$. The mesh (4) prevented the flocs from being flushed with the liquid.

To deoxygenate the flocs, medium free of $\mathrm{O}_{2}$ from the reservoir was then transferred (valve 9a) to the measuring chamber. This procedure was repeated till a low $(\leqslant 2 \%)$, stable value of dissolved $\mathrm{O}_{2}$ was displayed.

The remaining liquid in the reservoir was then saturated with air. Once this operation was finished, the air free medium in the measuring chamber was replaced by the air saturated medium from the reservoir and the data acquisition was started.
During the experiment, the maintenance of the size of the flocs withdrawn from the bioreactor was ensured by the adjustment of an appropriate stirring speed and checked by an image analysis technique (Vicente $e t$ al., 1996).

\section{Data acquisition and treatment}

The signal from the probe was measured every $2 \mathrm{~s}$ via a LABTECH NOTEBOOK Ltd. Build Time (USA) data acquisition card supported with a corresponding software installed in a personal computer.

Raw, oscillating data were smoothed applying Fast Fourier Transformation techniques.

Assuming that oxygen uptake by the cells follows a Monod type kinetics, the corresponding parameters were determined fitting data by means of non-linear regression (Dluhý and Báleš, 1996).

\section{Results and discussion}

This system has been designed especially for the evaluation of kinetic and mass transfer parameters in cell 
aggregates of other fragile particles. To test the above mentioned equipment an experiment was performed with glucose as the carbon source. During its course, the decrease of the dissolved oxygen concentration was measured and neither physical nor metabolic changes were observed in the aggregares.

Parameters of a Monod type kinetics,

$$
r_{C}=-p_{1} \cdot C \cdot X /\left(p_{z}+C\right)
$$

were successfully calculated applying a non-linear regression method with the residual sum of squares (RSS) as the objective function. In Eq. (1) $r_{c}$ is the oxygen uptake rate $\left(\mathrm{mg} \mathrm{O}_{2} /(\mathrm{L} \cdot h)\right)$ from which $q_{02}$, can be calculated, $C$ is the dissolved oxygen concentration ( $\left.m g \mathrm{O}_{2} / \mathrm{L}\right), X$ is the active biomass concentration $(\mathrm{g} / \mathrm{L})$, $p_{1}$ corresponds to $q_{(j 2, \max }\left(\mathrm{mg} \mathrm{O} \mathrm{O}_{2} /(\mathrm{g}(\mathrm{h}))\right.$ and $p_{2}$ corresponds to $K_{m}\left(\mathrm{mg} \mathrm{O} \mathrm{O}_{2} / \mathrm{L}\right)$.

Although Eq. (1) represents a Monod type kinetic model, calculated values of $p_{1}$ and $p_{2}$ are only apparent and have no direct relation to the usual kinetic parameters. The designations $q_{()_{2} m_{x x}}$ and $K_{m}$ were not used here as they could induce the reader in error: usually they are applied for cultures of suspended free cells; in the present case, cell aggregates were studied, instead, altering significantly the overall behavior of the system and, therefore, the meaning of those parameters.

Fig. 2 illustrates the course of the experimental run. The curve resulting from the fit of data to the Monod type kinetic model is also shown. The corresponding

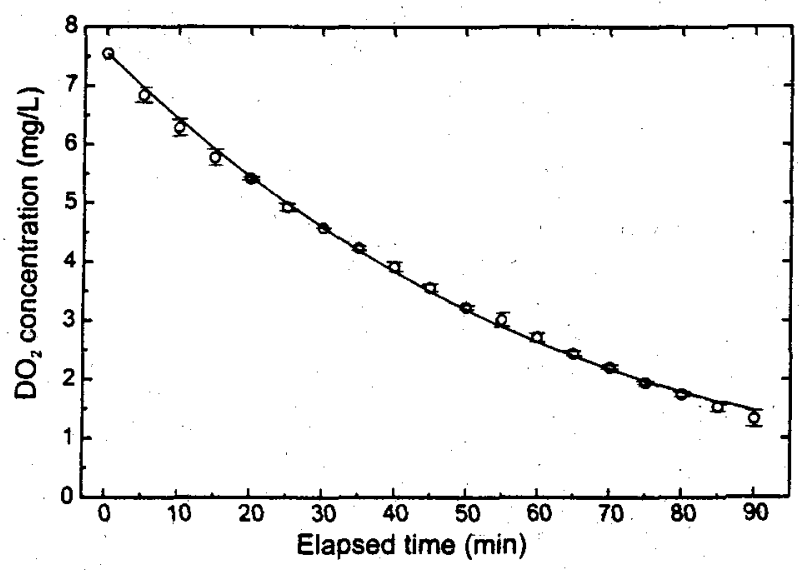

Figure 2 Experimental data (O) obtained during the measuring after treatment by Fast Fourier Transformation (for clarity not all points are shown) and the corresponding fit $(-)$ to Monod type kinetics. values of the parameters are $p_{1}=50.65 \pm 11.65 \mathrm{mg}$ $\mathrm{O}_{2} /(\mathrm{g} \cdot \mathrm{h}), p_{2}=20.40 \pm 5.84 \mathrm{mg} \mathrm{O}_{2} / \mathrm{L}$ (RSS $=0.12312$ $\left.\mathrm{mg}^{2} \mathrm{O}_{2} / \mathrm{L}^{2}\right)$. The $q_{02}$ value is approximately $32 \mathrm{mg}$ $\mathrm{O}_{2} /(\mathrm{L} \cdot \mathrm{h})$.

In Fig. 2 it is clearly shown that the curve fit and data points are in very good agreement, and that is confirmed by the comparatively low values of the RSS.

In spite of the considerably strong correlation between the kinetic paramerers (corresponding elements of the covariance matrix around 0.95 ) which would indicate some inappropriateness of the model, and despite the consequentially high maximum errors obtained for the estimated parameters, the results can be regarded to be reliable within the total experimental error $(-2 \%)$.

Oxygen uptake rate depends on several factors: type of strain, culture conditions,' physiological state of the culture. This makes difficult the task of comparing data from different sources. Due to mechanical fragility of the yeast flocs, only a small amount of data for that kind of aggregates can be found in the literature. In general, for gel immobilized cells and cell suspensions, values of $q_{02}$ as high as $112-720 \mathrm{mg} \quad O_{2} /(\mathrm{L} \cdot \mathrm{h})$ are reported (Kurosawa, 1989; Sato and Toda, 1983; Sonnleitner and Hahnemann, 1994; Sousa and Teixeira, 1996). In comparison, values for plant aggregates are significantly lower (2.1-3.1 $\mathrm{mg} \mathrm{O}_{2} /(\mathrm{L} \mathrm{h})$ ) (Ananta et al., 1995).

The very high value of $p_{2}$ (corresponding to an apparent $K_{m}$ for the flocs) rose the suspicion of an important

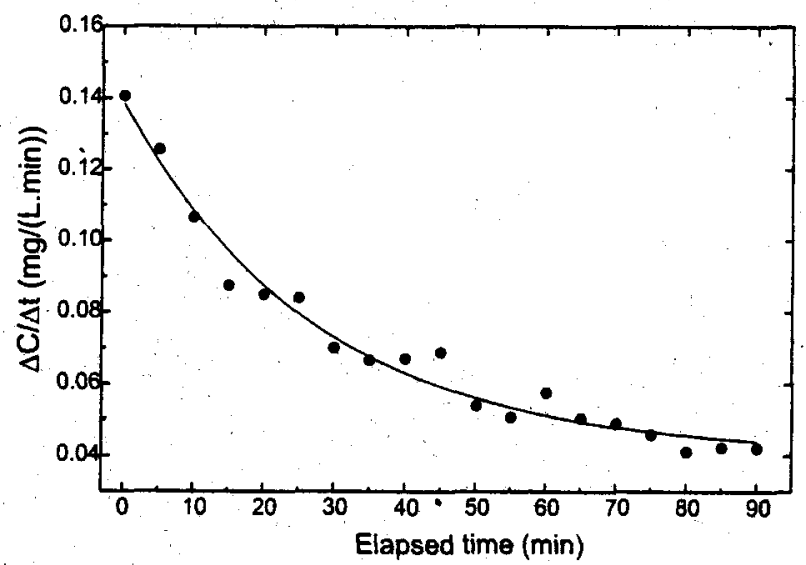

Figure 3 Finite differences method applied to the experimental data (O); $\Delta C$ and $\Delta t$ are the finite differences for $\mathrm{O}_{2}$ concentration and time, respectively, between two consecutive points. An exponential curve $(-)$ was adjusted to the dąta points in order to make evident their trend. 
internal resistance to oxygen transfer into the flocs: If only respiration would occur, withour limitations of any kind, a constant oxygen uptake rate would be observed. Fig. 3 shows the evolution of thar rate with time. As can be clearly seen, it diminishes exponentially during the course of the experiment. This means that the oxygen reaching the cells in the interior of the flocs becomes limiting; therefore, even neglecting external resistance, the internal mass transfer resistance plays an important role. Further, the successively lower value of oxygen uptake rate is caused by the correspondingly lower driving force of the process in the system due to depletion of oxygen.

The results obtained in this study for the specific oxygen uptake rate of the flocs $(32 \mathrm{mgO} / /(\mathrm{L} \cdot h))$, making use of the system described above, are in very good agreement with those published by Sousa and Teixeira, $1996(36 \mathrm{mg} \mathrm{O} /(\mathrm{L} \cdot \mathrm{h})$ ) for the same yeast strain grown under identical conditions. This shows that both the equipment and the procedure presented herein are suitable for the objectives for which they have been designed and developed. Further, preliminary experiments made with calcium alginate beads (results not shown) corroborate the above conclusions and confirm the applicability of the apparatus for other high cell density or enzyme immobilization systems.

To determine real parameters of a Monod rype kinetic model $\left(q_{12, \text { max }}\right.$ and $\left.K_{m}\right)$ free from the diffusional limirations' influence, it would be necessary to calculate the dependence of the effectiveness factor $(\eta)$ versus the Thiele modulus $(\phi)$, which compares the relative magnitude of reaction and diffusion. From the kind of dara obrained with the present apparatus it is also possible to calculate mass transfer parameters, allowing for a complete characterizarion of the cell aggregates.

\section{Acknowledgements}

The financial support of J.N.I.C.T. (Junta Nacional de Investigação Científica e Tecnológica) and N.A.T.O. is gratefully acknowledged.

\section{References}

Ananta, I., Subroto M.A. and Doran, P.M. (1995). Biotecbnol. Bioeng. 47, 541-549.

Dluhý, M. and Báleš, V. (1996). Polish J. Euviron. Studies 5(4), $9-15$.

Galazzo, J.L. and Bailey, J.E. (1990). Biotech. Bioeng. 36, $417-426$.

Gianerto, A., Ruggeri, B., Specchia, V., Sassi, G. and Forna, R. (1988). Chem. Eng. Sci. 43, 1891-1896.

Hamdi, M. (1995). Bioprocess Eng. 12, 193-197

Handriková, G., Štefuca, V., Polakovic, M. and Báleš, V. (1996). Enzymie Microb. Technol. 18, 581-584.

Katzbauer, B., Narodoslawsky, M. and Moser, A. (1995). Bioprocess Eng. 12, 173-179.

Kurosawa, H., Matsumura M. and Tanaka, H. (1989). Bintechnol. Bineing. 34, 926-932.

Laplace, J.M., Delgenes, J.P., Moletta. R. and Navarro, J.M. (1993). Proc: Biochem. 28, 519-525.

Øyaas, J., Storrø, I., Svendsen, H. and Levine, D. W. (1995) Biotechnol. Bioeng. 47, 492-500.

Pereboom, J.H.F., van den Heuvel, J.C., Ottengraf, S.P.P., Huisman, J.W. and de Beer, D. (1990). Proceedings of the 3rd Netberlands Biotechnology Congress, Part II.

Riley, M.R., Muzzio, F.J., Buettner, H.M. and Reyes, S.C. (1996). Biotechnol. Bioeng. 49, 223-227.

Sato, K. and Toda, K.(1983). J. Ferment. Tetbnol. 61, 239-245.

Sonnleitner, B. and Hahnemann, U. (1994). J. Biosechnol. 88. $6 j-79$.

Sousa, M.L. and Teixeira, J.A. (1991). Biotechnol. Lett. L3, $883-888$.

Sousa, M.L. and Teixeira, J.A. (1996). Biotechnol. Lett. is, 229-234.

Sousa, M.L., Teixeira, J.A. and Mota, M. (1994). Bioprocess Engr. $11,83-90$.

Tanaka, H., Marsumura, M. and Veliky, I.A. (1984). Biofethol. Bioeng, 26, 53-58.

Teixeira, J.A. and Mora, M. (1990). Chem. Eng. J. 43, Bl3-BL ?. Vicente, A., Meinders, J.M. and Teixeira, J.A. (1996). Biotechnol. Bioeng. 51, 673-678.

Vicente, A.A. and Teixeira, J.A. (1995). Bioprocess Eng. 14, 17-22.

Willaert, R.G. and Baron, G.V. (1994). Biotechnol. Teth. 8, 695-700). 